\title{
Enhancement by isosorbide dinitrate of haemodynamic effects of dopamine in chronic congestive cardiac failure
}

\author{
JOHN STEPHENS, DUNCAN DYMOND, AND ROWORTH SPURRELL \\ From the Department of Cardiology, St. Bartholomews Hospital, London
}

SUMMARY The haemodynamic effects of dopamine and isosorbide dinitrate alone and in combination were studied in 8 patients with chronic congestive cardiac failure. In 7 patients dopamine, $6 \mu \mathrm{g} / \mathrm{kg}$ per min, increased mean cardiac index from 2.0 to $3.01 / \mathrm{min}_{\text {per }} \mathrm{m}^{2}(\mathrm{P}<0.0005)$; mean stroke volume index from 20 to $27 \mathrm{ml} / \mathrm{m}^{2}(\mathrm{P}<0.0025)$, and mean left ventricular stroke work index from 14 to $20 \mathrm{~g}$ $\mathrm{m} / \mathrm{m}^{2}(\mathrm{P}<0.0025)$. Mean left ventricular filling pressure did not change significantly. Isosorbide, 5 to $10 \mathrm{mg}$ sublingually, reduced mean left ventricular filling pressure from 29 to $24 \mathrm{mmHg}$ $(P<0.0005)$ and mean arterial pressure from 80 to $73 \mathrm{mmHg}(P<0.01)$, with no significant change in mean cardiac index, stroke volume index, or left ventricular stroke work index. When dopamine was reinfused after isosorbide administration mean cardiac index increased to $3.21 / \mathrm{min}$ per $\mathrm{m}^{2}$, stroke volume index to $31 \mathrm{ml} / \mathrm{m}^{2}$ (P $<0.05$ vs dopamine alone), and left ventricular stroke work index to $23 \mathrm{~g} \mathrm{~m} / \mathrm{m}^{2}$ $(\mathrm{P}<0.0125$ vs dopamine alone). Mean left ventricular filling pressure rose slightly to $25 \mathrm{mmHg}$ but this was significantly less than for dopamine alone $(P<0.0005)$. In an eighth patient, whose left ventricular filling pressure fell to $12 \mathrm{mmHg}$ after isosorbide, the reinfusion of dopamine was associated with severe bradycardia and hypotension, which responded to the intravenous administration of atropine.

Afterload reduction with isosorbide combined with inotropic stimulation with dopamine may produce greater improvement in left ventricular performance in patients with congestive cardiac failure than either drug alone. Such treatment should be used with caution possibly in patients whose left ventricular filling pressure falls into the lower range after isosorbide alone.

Isosorbide dinitrate has been shown to be effective in reducing left ventricular filling pressure in patients with chronic congestive cardiac failure (Franciosa et al., 1974; Gray et al., 1975; Williams et al., 1977) though the improvement in other aspects of left ventricular function such as cardiac output appears to be modest.

This study was designed to examine the possibility that the combination of isosorbide and an inotropic agent may be a more effective form of therapy for patients requiring intensive treatment for severe congestive cardiac failure. Dopamine is a short acting inotropic drug which has been shown to be effective in the treatment of congestive cardiac failure (Beregovitch et al., 1974) and was, therefore, selected for the study.

Received for publication 11 October 1977.

\section{Patients and methods}

Eight patients with severe congestive cardiac failure were studied. Informed consent was obtained in all cases. Five patients were studied during an intensive treatment programme for severe intractable congestive cardiac failure. The remaining 3 patients were studied at the time of haemodynamic assessment for long-term isosorbide therapy for less severe, though disabling congestive cardiac failure. The aetiology was ischaemic heart disease in all but one patient who developed severe congestive cardiac failure in the early postoperative period after mitral valve replacement for mitral stenosis. This patient's left ventricular function was found to be normal at cardiac catheterisation before the operation. There was no evidence on clinical and echocardiographic grounds for prosthetic valve dysfunction. Isotope ventriculography indicated a severe reduction in 
Table 1 Patient data

\begin{tabular}{|c|c|c|c|c|c|}
\hline Case & Age & Sex & History & Catheterisation findings & Clinical course \\
\hline 1 & 51 & $\mathbf{M}$ & $\begin{array}{l}\text { Recent mitral valve replacement; } \\
\text { developed severe CCF postoperatively }\end{array}$ & - & $\begin{array}{l}\text { Discharged on ISDN and diuretics; } \\
\text { died after } 3 \text { months }\end{array}$ \\
\hline 2 & 62 & $\mathbf{M}$ & $3 \mathrm{MIs}$; admitted in pulmonary oedema & - & Discharged on ISDN and diuretics \\
\hline 3 & 58 & $\mathbf{M}$ & 2 MIs; severe exertional dyspnoea & $\begin{array}{l}\text { Diffuse impairment of } L V \text { function; } \\
3 \text { vessel CAD }\end{array}$ & Discharged on ISDN and diuretics \\
\hline 4 & 52 & $\mathbf{M}$ & $\begin{array}{l}2 \text { MIs; angina and severe exertional } \\
\text { dyspnoea }\end{array}$ & $\begin{array}{l}\text { Diffuse impairment of } L V \text { function; } \\
2 \text { vessel disease }\end{array}$ & Discharged on ISDN and diuretics \\
\hline 5 & 52 & $\mathbf{M}$ & $\begin{array}{l}\text { Massive AMI requiring IABP assist; } \\
\text { severe dyspnoea since discharge }\end{array}$ & - & Discharged on ISDN and diuretics \\
\hline 6 & 67 & $\mathbf{M}$ & $\begin{array}{l}1 \mathrm{MI} \text {, angina and severe exertional } \\
\text { dypsnoea; developed severe CCF } \\
\text { while awaiting surgery }\end{array}$ & $\begin{array}{l}\text { Large dyskinetic area of } L V \text {; } \\
2 \text { vessel CAD }\end{array}$ & $\begin{array}{l}\text { Underwent LV aneurysmectomy; } \\
\text { died perioperatively }\end{array}$ \\
\hline 7 & 49 & $\mathbf{M}$ & 2 MIs admitted in severe CCF & $\begin{array}{l}\text { Diffuse impairment of } L V \text { function; } \\
3 \text { vessel CAD }\end{array}$ & $\begin{array}{l}\text { IABP assist required because of } \\
\text { systemic hypotension; died after } \\
2 \text { weeks }\end{array}$ \\
\hline 8 & 62 & $\mathbf{M}$ & $1 \mathrm{MI}$; angina and exertional dyspnoea & Diffuse impairment of $L V$ function & Discharged on ISDN and diuretics \\
\hline
\end{tabular}

Abbreviations: CCF, congestive cardiac failure; MI, myocardial infarction; LV, left ventricle; CAD, coronary arterv disease ( $>50 \%$ stenosis): IABP, intra-aortic balloon pump; ISDN, isosorbide dinitrate.

left ventricular ejection fraction wih diffuse hypokinesis. He was, therefore, assumed to have sustained severe heart muscle damage in the intraoperative or early postoperative period.

Patient data are presented in Table 1.

All studies were carried out in the coronary care unit. No drugs had been given within 4 hours of the start of the study though current treatment was not modified. A Waters thermodilution catheter was advanced to the pulmonary artery from a subclavian vein using a Desilet Hoffman No. 8 cannula. A 20 gauge cannula was inserted into the radial or brachial artery transcutaneously. Lead II of the electrocardiogram was recorded. Pulmonary arterial and systemic arterial pressures were measured using Elcomatic transducers and displayed on a Sanborn 780-6A Viso Scope (Hewlett-Packard).

For convenience, changes in the pulmonary arterial end-diastolic pressure were taken to represent changes in left ventricular filling pressure (Bouchard et al., 1971; Mantle et al., 1976;Bussmann et al., 1977).

Cardiac output was measured by the thermodilution technique (Ganz and Swan, 1972) using a Waters Cardiac Output Computer.

Control readings of heart rate, pulmonary arterial and systemic arterial pressures, and cardiac output were made. In addition, the frequency of ventricular ectopic beats when present was recorded during a 10-minute control period. Dopamine $6 \mu \mathrm{g} / \mathrm{kg}$ per min was then infused using a Harvard pump for 15 minutes at which time measurements were repeated. The infusion was then discontinued. After 15 minutes and further control measurements isosorbide $5 \mathrm{mg}$ was administered sublingually. If no fall in left ventricular filling pressure was seen a further $5 \mathrm{mg}$ was given. After 10 minutes measure- ments were repeated. Dopamine was then reinfused at the same dose rate for 15 minutes when measurements were repeated.

Although the study was completed without incident in 7 patients, in one (case 8) a pronounced sinus bradycardia (40 beats/minute with junctional escape beats) developed after 5 minutes of the second dopamine infusion. There was hypotension (systolic arterial pressure $60 \mathrm{mmHg}$ ) with diaphoresis associated with a profound fall in pulmonary arterial pressure (pulmonary arterial end-diastolic pressure < $10 \mathrm{mmHg}$ ). The bradycardia was promptly reversed by discontinuing the dopamine infusion and the administration of atropine $0.6 \mathrm{mg}$ intravenously. Systemic arterial and pulmonary arterial pressures gradually returned to control within 45 minutes. Until this episode haemodynamic changes had followed a similar pattern to that observed in the other patients. There were no further complications.

CALCULATIONS

Mean arterial pressure $(\overline{\mathrm{AP}}) \mathrm{mmHg}$

$$
=\mathrm{D}+\frac{\mathrm{S}-\mathrm{D}}{3} \quad \text { (Yang et al., 1972) }
$$

where $\mathrm{D}=$ arterial end-diastolic pressure and $\mathrm{S}=$ peak systolic arterial pressure. Mean pulmonary arterial pressure $(\overline{\mathrm{PA}})$ was calculated in the same way.

Cardiac index $1 / \mathrm{min}$ per $\mathrm{m}^{2}=$ cardiac output (CO)/body surface area.

Stroke volume index (SVI) $\mathrm{ml} / \mathrm{m}^{2}=$ stroke volume/body surface area.

Left ventricular stroke work index $\mathrm{g} \mathrm{m} / \mathrm{m}^{2}$

$$
=(\overline{\mathrm{AP}})-\text { PAEDP }) \times \text { SVI } \times 0.0136
$$

where PAEDP $=$ pulmonary arterial end-diastolic pressure. 
Total systemic vascular resistance, dynes $\mathrm{s} \mathrm{cm}^{-5}$

$$
=\overline{\mathrm{AP}} / \mathrm{CO} \times 80
$$

Pulmonary vascular resistance, dynes $\mathrm{s} \mathrm{cm}^{-5}$

$$
=(\overline{\mathrm{PA}}-\mathrm{PAEDP}) / \mathrm{CO} \times 80
$$

Statistical analysis was by the paired Student's t test.

\section{Results}

\section{HAEMODYNAMIC EFFECTS}

(Data for the patient who developed severe bradycardia are not included but illustrated separately in Fig. 5).

\section{EFFECTS OF DOPAMINE}

Mean cardiac index increased from 2.0 to 3.0 $1 / \mathrm{min} / \mathrm{m}^{2}(\mathrm{P}<0.0005)$, stroke volume index from 20 to $27 \mathrm{ml} / \mathrm{m}^{2}(P<0.0025)$, and left ventricular stroke work index from 14 to $20 \mathrm{~g} \mathrm{~m} / \mathrm{m}^{2}$ (P < 0.0025). Mean heart rate increased from 105 to 114 beats/minute $(P<0.05)$, while mean pulmonary vascular resistance fell from 197 to 158 dynes s $\mathrm{cm}^{-5}$ $(\mathrm{P}<0.025)$ and mean systemic vascular resistance from 1840 to 1328 dynes $\mathrm{s} \mathrm{cm}^{-5}(\mathrm{P}<0.01)$. Mean
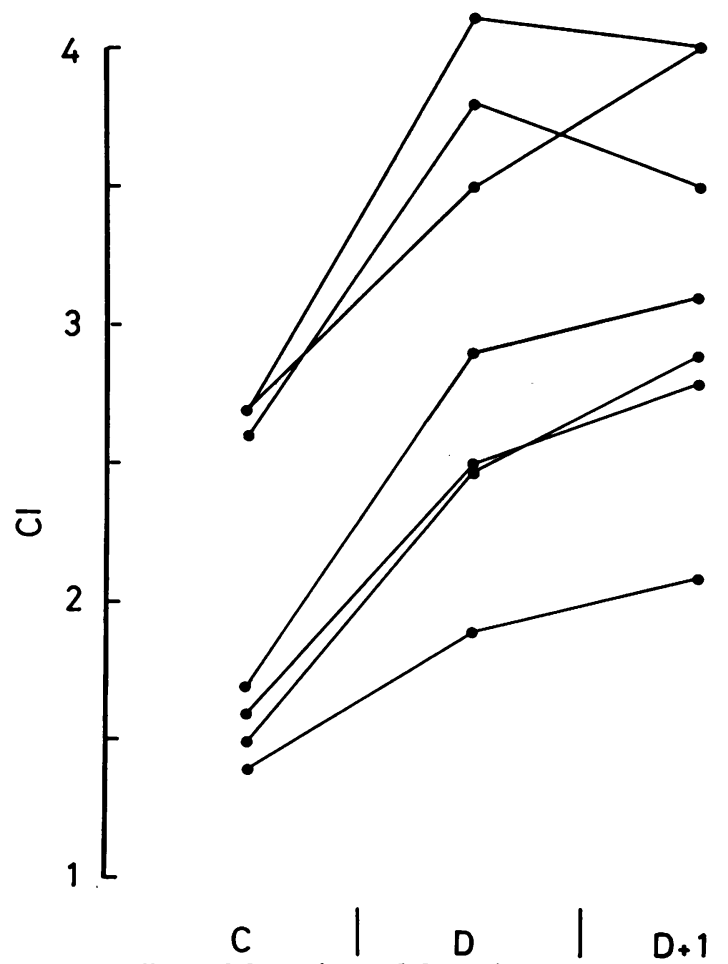

Fig. 1 Effects of dopamine and dopamine plus isosorbide on cardiac index $(C I) l /$ min per $m^{2} . C=$ control $D=$ dopamine. $I=$ isosorbide. pulmonary arterial pressure, pulmonary arterial end-diastolic pressure, and mean arterial pressure did not change significantly.

EFFECTS OF ISOSORBIDE

Mean pulmonary arterial end-diastolic pressure fell from 29 to $24 \mathrm{mmHg}(P<0.0005)$, mean arterial pressure from 80 to $73 \mathrm{mmHg}(P<0.01)$, and mean pulmonary arterial pressure from 37 to 32 $\mathrm{mmHg}(\mathrm{P}<0.01)$. There was no significant change in mean heart rate, cardiac index, stroke volume index, pulmonary vascular resistance, and left ventricular stroke work index. Mean systemic
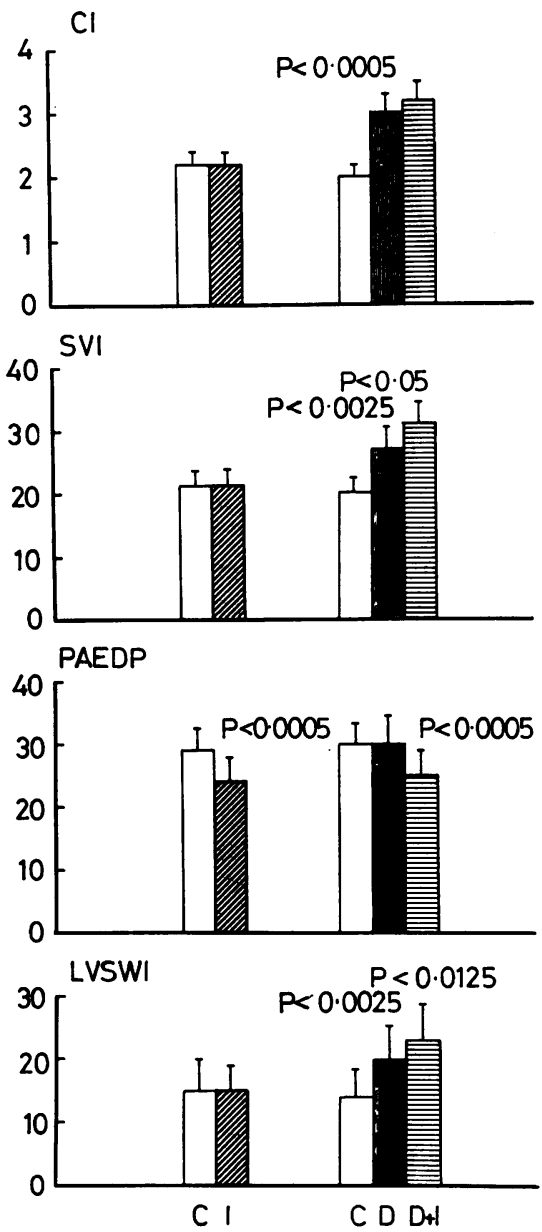

Fig. 2 Haemodynamic effects of dopamine $(D)$ and isosorbide (I) alone and in combination. CI, cardiac index l/min per $\mathrm{m}^{2} ; S V I$, stroke volume index, $\mathrm{ml} / \mathrm{m}^{2} ; P A E D P$ pulmonary arterial end-diastolic pressure, $\mathrm{mmHg}$;

LVSWI, left ventricular stroke work index, $\mathrm{g} \mathrm{m} / \mathrm{m}^{2}$; $C$, control. Values indicated are mean values. Bars represent standard error of mean. 


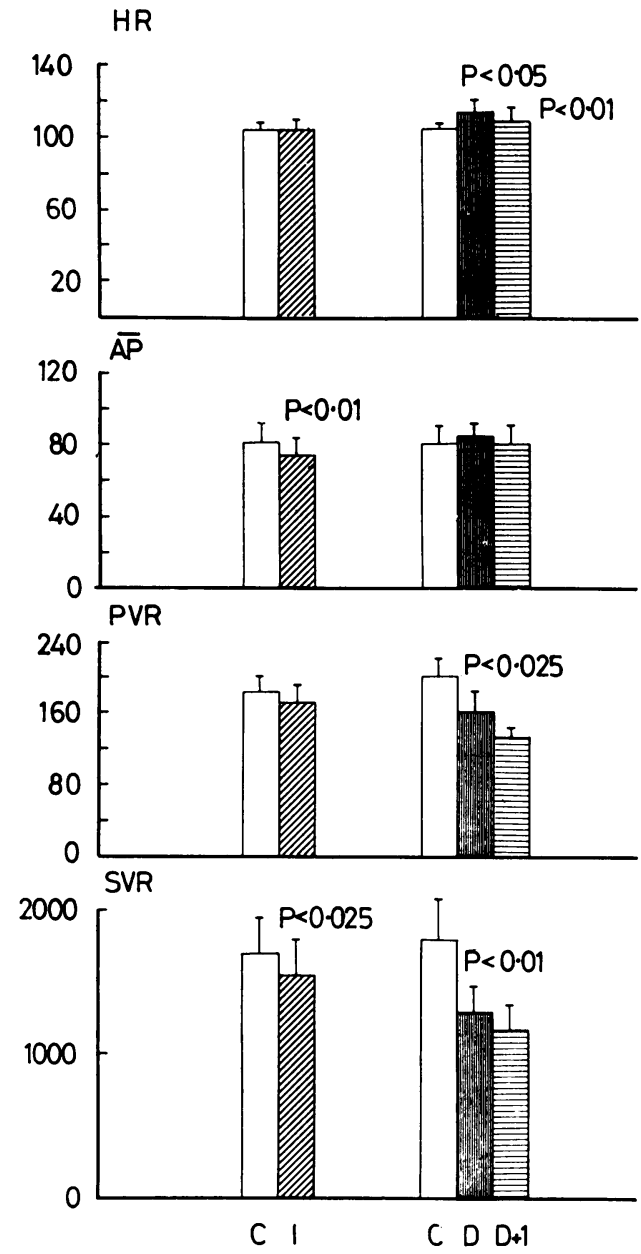

Fig. 3 Haemodynamic effects of dopamine (D) and isosorbide $(I)$ alone and in combination. $H R$, heart rate, beats/min; $\overline{A P}$, mean systemic arterial pressure, $\mathrm{mmHg}$; $P V R$, pulmonary vascular resistance, dynes $\mathrm{s} \mathrm{cm}^{-5}$; $S V R$, systemic vascular resistance, dynes $\mathrm{s} \mathrm{cm-5}$; $C$, control. Values indicated are mean values. Bars indicate standard error of mean.

vascular resistance fell from 1703 to 1554 dynes s $\mathrm{cm}^{-5}(\mathrm{P}<0.025)$.

\section{COMBINED EFFECTS OF DOPAMINE AND} ISOSORBIDE

There was a further increase in cardiac index in 5 patients and a slight fall in 2 compared with dopamine alone (Fig. 1). Compared with dopamine alone stroke volume index increased from 27 to 31 $\mathrm{ml} / \mathrm{m}^{2}(\mathrm{P}<0.05)$ and left ventricular stroke work index from 20 to $23 \mathrm{~g} \mathrm{~m} / \mathrm{m}^{2}(\mathrm{P}<0.0125)$. Compared with dopamine alone mean pulmonary arterial end-diastolic pressure fell from 30 to $25 \mathrm{~mm}$
$\mathrm{Hg}(\mathrm{P}<0.0005)$, and mean pulmonary arterial pressure from 40 to $34 \mathrm{mmHg}(\mathrm{P}<0.0025)$. There was a further fall in pulmonary and systemic vascular resistance in all but one patient compared with dopamine alone, with no significant change in the mean. There was a small but significant fall in mean heart rate (mean 5 beats $/$ minute, $P<0.01$ dopamine alone). Mean values for mean arterial pressure did not change significantly.

Changes in mean values are illustrated in Fig. 2 and 3; individual data are shown in Tables 2 to 4 .

\section{EFFECTS ON FREQUENCY OF VENTRICULAR} PREMATURE BEATS

Neither drug alone or in combination produced ventricular premature beats or significantly increased their frequency when present except in one patient (case 1) in whom they occurred frequently ( $35 /$ minute) during the control period. The frequency increased to $55 /$ minute during dopamine. During combined drug administration the frequency was $44 /$ minute. There were no serious arrhythmias such as ventricular tachycardia. No patient complained of angina pectoris during the study.

\section{Discussion}

The results of this study indicate that inotropic stimulation of the failing heart with dopamine is effective in improving certain aspects of left ventricular function, i.e. cardiac output and stroke volume. However, another important aspect of left ventricular performance, left ventricular filling pressure, may remain severely impaired. In the patient with severe congestive cardiac failure this assumes great importance since the consequences of a high left ventricular filling pressure are those of pulmonary venous congestion and consequent dyspnoea. Further, in the acutely ill patient with severe congestive cardiac failure, pulmonary arterial oxygenation may be compromised leading to systemic arterial hypoxaemia which may further impair cardiac performance, particularly in the presence of ischaemic heart disease.

Conversely isosorbide has been shown to reduce left ventricular filling pressure with little effect on cardiac output. Indeed, falls in cardiac output have been reported (Williams et al., 1977) possibly as a result of a fall in left ventricular filling pressure below optimal levels (Crexells et al., 1973). Thus, though pulmonary venous congestion may be effectively relieved, an associated fall in cardiac output may compromise renal perfusion leading to further sodium and water retention in patients whose cardiac output is already reduced to a critical level. 
Table 2 Haemodynamic effects of dopamine

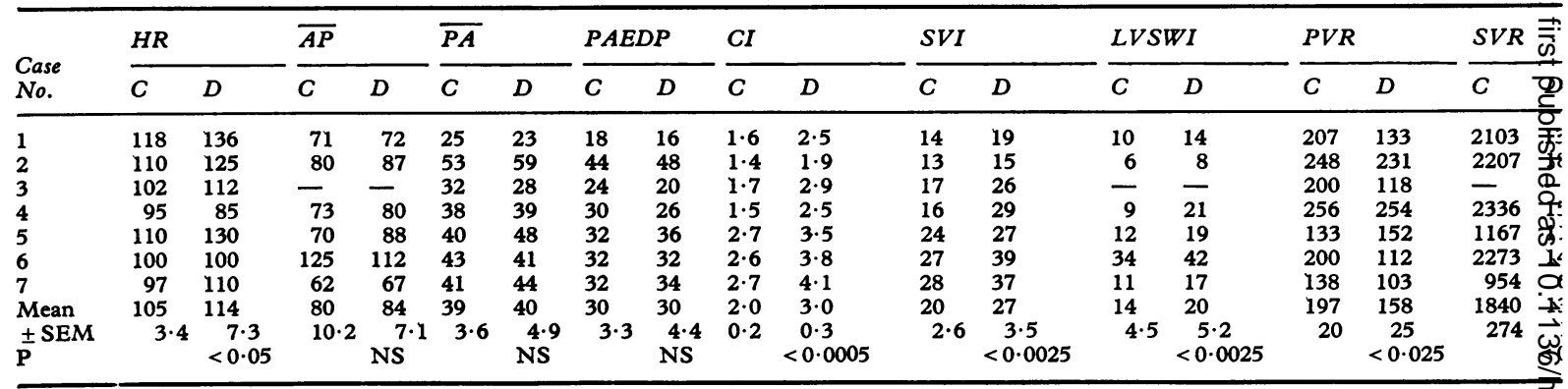

Abbreviations: HR, heart rate; $\overline{\mathrm{AP}}$, mean arterial pressure; $\overline{\mathrm{PA}}$, mean pulmonary arterial pressure; PAEDP, pulmonary arterial end-diastolic pressure cardiac index; SVI, stroke volume index; LVSWI, left ventricular stroke work index; PVR, pulmonary vascular resistance; SVR, systemic vascular resif SEM, standard error of mean; $C$, control; $D$, dopamine.

Table 3 Haemodynamic effects of isosorbide

\begin{tabular}{|c|c|c|c|c|c|c|c|c|c|c|c|c|c|c|c|c|c|}
\hline \multirow{2}{*}{$\begin{array}{l}\text { Case } \\
\text { No. }\end{array}$} & \multicolumn{2}{|l|}{$H R$} & \multicolumn{2}{|l|}{$\overline{A P}$} & \multicolumn{2}{|l|}{$\overline{P A}$} & \multicolumn{2}{|c|}{$P A E D P$} & \multicolumn{2}{|l|}{$C I$} & \multicolumn{2}{|l|}{$S V I$} & \multicolumn{2}{|c|}{$L V S W I$} & \multicolumn{2}{|c|}{$P V R$} & $S V R$ \\
\hline & $C$ & $I$ & $C$ & $I$ & $C$ & $I$ & $C$ & $I$ & $C$ & $I$ & $C$ & $I$ & $C$ & $I$ & $C$ & $I$ & $C$ \\
\hline $\begin{array}{l}1 \\
2 \\
3 \\
4 \\
5 \\
6 \\
7 \\
\text { Mean } \\
\pm \text { SEM } \\
\mathbf{P}\end{array}$ & $\begin{array}{r}119 \\
110 \\
108 \\
90 \\
115 \\
98 \\
95 \\
105 \\
4.4\end{array}$ & $\begin{array}{c}120 \\
117 \\
108 \\
86 \\
110 \\
98 \\
95 \\
105 \\
5 \cdot 0 \\
\mathrm{NS}\end{array}$ & $\begin{array}{c}71 \\
87 \\
- \\
63 \\
70 \\
125 \\
62 \\
80 \\
10 \cdot 7\end{array}$ & $\begin{array}{c}64 \\
83 \\
63 \\
62 \\
110 \\
55 \\
73 \\
9.1 \\
<0.01\end{array}$ & $\begin{array}{c}23 \\
54 \\
29 \\
38 \\
40 \\
37 \\
41 \\
37 \\
4 \cdot 0\end{array}$ & $\begin{array}{c}17 \\
50 \\
25 \\
28 \\
35 \\
33 \\
33 \\
32 \\
4 \cdot 2 \\
<0.01\end{array}$ & $\begin{array}{l}16 \\
44 \\
22 \\
30 \\
32 \\
28 \\
32 \\
29 \\
3.6\end{array}$ & $\begin{array}{l}10 \\
40 \\
18 \\
20 \\
28 \\
24 \\
25 \\
24 \\
3.8 \\
<0.0005\end{array}$ & $\begin{array}{l}1 \cdot 8 \\
1 \cdot 4 \\
1 \cdot 7 \\
1 \cdot 8 \\
2 \cdot 7 \\
2 \cdot 8 \\
2 \cdot 9 \\
2 \cdot 2 \\
0 \cdot 2\end{array}$ & $\begin{array}{l}1 \cdot 6 \\
1 \cdot 5 \\
1 \cdot 8 \\
2 \cdot 0 \\
3 \cdot 2 \\
2 \cdot 7 \\
2 \cdot 5 \\
2 \cdot 2 \\
0 \cdot 2 \\
\text { NS }\end{array}$ & $\begin{array}{c}15 \\
13 \\
16 \\
20 \\
23 \\
28 \\
30 \\
21 \\
2 \cdot 7\end{array}$ & $\begin{array}{c}13 \\
13 \\
16 \\
22 \\
29 \\
28 \\
26 \\
21 \\
2 \cdot 8 \\
\text { NS }\end{array}$ & $\begin{array}{r}11 \\
8 \\
-9 \\
12 \\
37 \\
12 \\
15 \\
4.9\end{array}$ & $\begin{array}{c}9 \\
8 \\
13 \\
13 \\
33 \\
11 \\
15 \\
4 \cdot 1 \\
\text { NS }\end{array}$ & $\begin{array}{r}187 \\
276 \\
181 \\
213 \\
133 \\
156 \\
131 \\
182 \\
21\end{array}$ & $\begin{array}{c}207 \\
258 \\
170 \\
194 \\
98 \\
160 \\
136 \\
175 \\
21 \\
\text { NS }\end{array}$ & $\begin{array}{r}1893 \\
2400 \\
- \\
1680 \\
1167 \\
2174 \\
902 \\
1703 \\
259\end{array}$ \\
\hline
\end{tabular}

Abbreviations: HR, heart rate; $\overline{\mathbf{A P}}$, mean arterial pressure; $\overline{\mathbf{P A}}$, mean pulmonary arterial pressure; PAEDP, pulmonary arterial end-diastolic pressuㅏㅁ cardiac index; SVI, stroke volume index; LVSWI, left ventricular stroke work index; PVR, pulmonary vascular resistance; SVR, systemic vascular reş3t SEM, standard error of mean; $C$, control; $I$, isosorbide.

Table 4 Haemodynamic tfects of dopamine vs dopamine and isosorbide

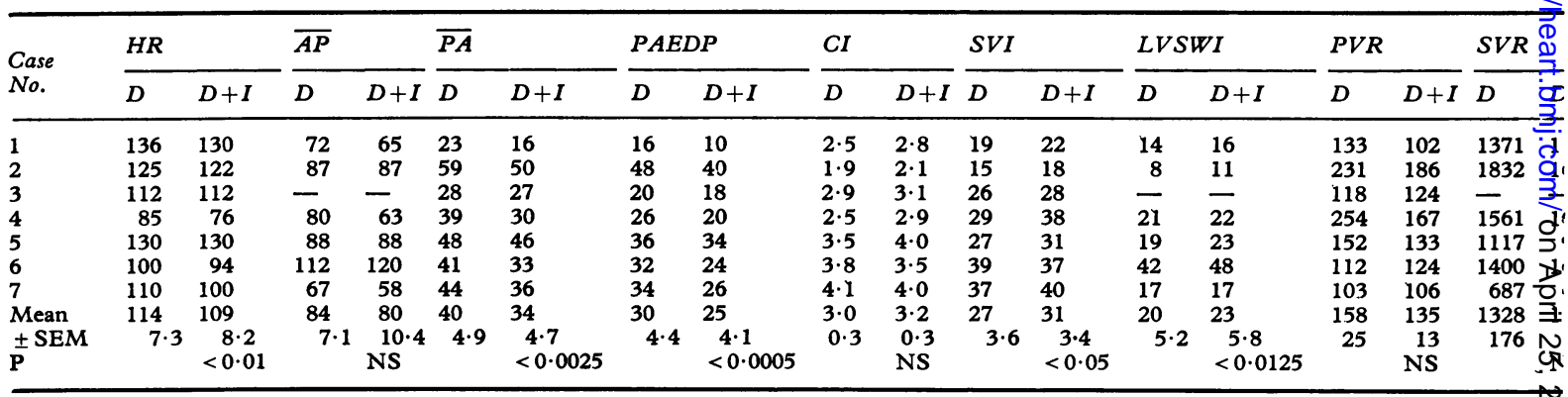

Abbreviations: HR, heart rate; $\overline{\mathrm{AP}}$, mean arterial pressure; $\overline{\mathrm{PA}}$, mean pulmonary arterial pressure; PAEDP, pulmonary arterial end-diastolic pressur cardiac index; SVI, stroke volume index; LVSWI, left ventricular stroke work index; PVR, pulmonary vascular resistance; SVR, systemic vascular ref(s) SEM, standard error of mean; $D$, dopamine; $I$, isosorbide.

The principal actions of isosorbide on the peripheral vasculature appear to be those of arteriolar vasodilatation and venodilatation (Mason and Braunwald, 1965). The former reduces left ventricular afterload which Cohn (1973) argues is primarily responsible for the haemodynamic improvement reported in patients with congestive cardiac failure treated with certain vasodilators; the fall in the left ventricular filling pressure observed with vasodilator therapy may be secondary to the reduction in afterload or because of dilatation of venous capacitance vessels. 


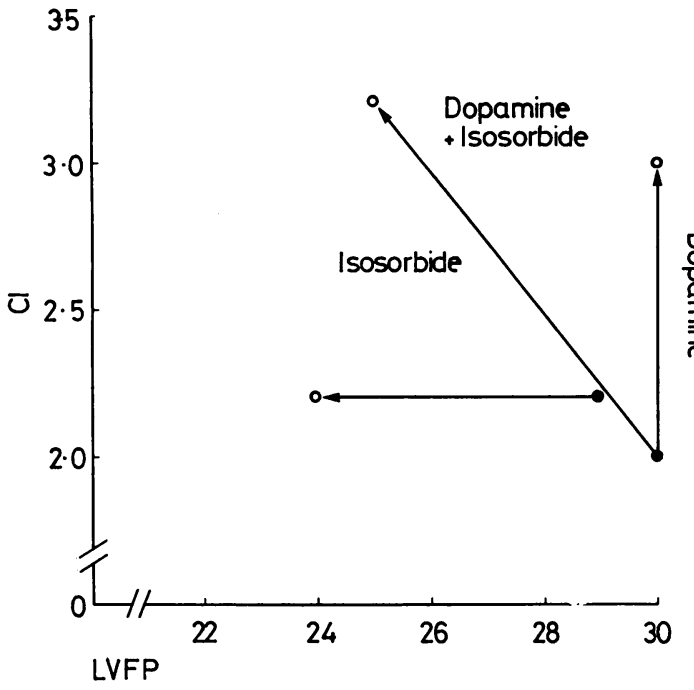

Fig. 4 Relation between left ventricular filling pressure $(L V F P) \mathrm{mmHg}$ and cardiac index (CI) $l / \mathrm{min}$ per $\mathrm{m}^{2}$. The arrows show the direction of change from control (closed circles) to the intervention indicated (open circles).

Dopamine is an inotropic drug which has a vasoconstrictor effect on certain peripheral vascular beds (Mark et al., 1970; Higgins et al., 1973). In congestive cardiac failure these actions may have the undesirable effects of increasing left ventricular afterload and venous return; the former through arteriolar vasoconstriction and the latter through constriction of venous capacitance vessels. These effects may explain the failure of dopamine to reduce left ventricular filling pressure in congestive cardiac failure (Loeb et al., 1971).

The hypothesis that combined therapy with an inotropic drug and a vasodilator will have a synergistic effect on the failing heart has been supported by the observation of this study. Thus the principal cardiac therapeutic effect of dopamine (increase in cardiac output and stroke volume) has been combined with that of isosorbide (reduction in left ventricular filling pressure) to achieve a more comprehensive improvement in left ventricular performance (Fig. 4). Afterload reduction by isosorbide, therefore, augments the effects of dopamine on stroke volume and cardiac output which in turn maintains arterial pressure. These effects, possibly combined with the venodilating effect of isosorbide, lead to a reduction in left ventricular filling pressure.

That the enhancement of the effects of an inotropic drug by a vasodilator may be achieved with an attenuation or reduction in myocardial oxygen consumption is an attractive hypothesis. A reduc-
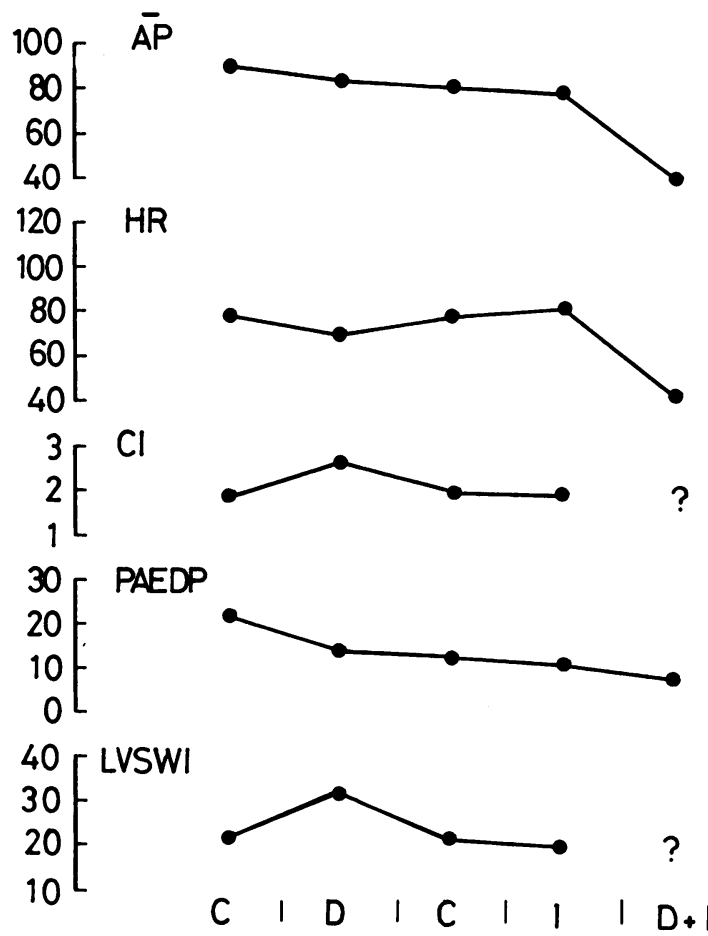

Fig. 5 Haemodynamic changes in the patient (case 8) who developed severe bradycardia and hypotension. $\overline{A P}$, mean systemic arterial pressure, $\mathrm{mmHg} ; \mathrm{HR}$, heart rate, beats/minute; CI, cardiac index, l/min per $\mathrm{m}^{2}$; $P A E D P$, pulmonary arterial end-diastolic pressure, $\mathrm{mmHg}$; LVSWI, left ventricular stroke work index, $\mathrm{g} \mathrm{m} / \mathrm{m}^{2}$; $C$, control; $D$, dopamine; $I$, isosorbide.

tion in left ventricular wall tension achieved by the vasodilator consequent upon reductions in preload and afterload would reduce myocardial oxygen consumption though an increase in myocardial contractility would have the opposite effect (Graham et al., 1968). Further investigation is required to determine the net effect of changes in such variables which influence myocardial oxygen consumption. The attenuation of inotropically induced increases in myocardial oxygen consumption would clearly be an advantage in patients with ischaemic heart disease, particularly those with recent myocardial infarction.

Although the patients presented in this study were those with chronic congestive cardiac failure it is possible that the use of combined dopamine and isosorbide therapy may have a place in the management of patients with congestive cardiac failure or cardiogenic shock after acute myocardial infarction. In addition to the advantage of such therapy with regard to myocardial oxygen consumption discussed above, there is the possibility that it may be 
applicable in hypotensive states where isosorbide therapy alone may be contraindicated, since in this study the reinfusion of dopamine after isosorbide administration counteracted the hypotensive effect of the latter.

The reason for the occurrence of the severe bradycardia in one patient is obscure. It occurred in association with a pronounced fall in left ventricular filling pressure which may have caused the observed precipitous fall in cardiac output and arterial pressure. However, such a chain of events would be expected to produce a tachycardia through the baroreceptor reflex. A similar syndrome has been reported in association with intravenous nitroglycerin administration (Come and Pitt, 1976) in patients with acute myocardial infarction. These authors suggested several possible mechanisms including vagal stimulation through pressure or length receptors in the right atrium or left ventricle. Since the bradycardia in our patient responded quickly to atropine, vagal discharge appears to be the final common pathway involved in its genesis. It is possible that a lesser degree of vagal discharge occurred in all patients when dopamine was reinfused, which may explain the observed small fall in heart rate compared with the first infusion period.

Thus, though combined therapy with dopamine. and isosorbide offers a promising new approach in the treatment of severe congestive cardiac failure it should be used with caution, perhaps more so in the patient whose left ventricular filling pressure falls in the lower range after isosorbide administration.

The authors acknowledge the assistance of Dr A.T. Mennie and Mr B. G. Tyrwhitt-Drake of ArnarStone Laboratories.

\section{References}

Beregovich, J., Bianchi, C., Rubler, S., Lomnitz, E., Cagin, N., and Levitt, B. (1974). Dose-related hemodynamic and renal effects of dopamine in congestive cardiac failure. American Heart fournal, 87, 550-557.

Bouchard, R. J., Gault, J. H., and Ross, J., Jr. (1971). Evaluation of pulmonary arterial end-diastolic pressure as an estimate of left-ventricular diastolic pressure in patients with normal and abnormal left ventricular performance. Circulation, 44, 1072-1079.

Bussmann, W. D., Löhner, J., and Kaltenbach, M. (1977). Orally administered isosorbide dinitrate in patients with and without left ventricular failure due to acute myocardial infarction. American fournal of Cardiology, 39, 91-96.

Cohn, J. N. (1973). Vasodilator therapy for heart failurethe influence of impedance on left ventricular performance. Circulation, 48, 5-7.

Come, P. C., and Pitt, B. (1976). Nitroglycerin induced severe hypotension and bradycardia in patients with acute myocardial infarction. Circulation, 54, 624-628.

Crexells, C., Chatterjee, K., Forrester, I. S., Dikshit, K., and Swan, H. J. C. (1973). Optimal level of filling pressure in ڤ the left side of the heart in acute myocardial infarction. New England fournal of Medicine, 289, 1263-1266.

Franciosa, J. A., Mikulic, E., Cohn, J. N., Jose, E., and Fabie, A. (1974). Hemodynamic effects of orally administered isosorbide dinitrate in patients with congestive cardiac failure. Circulation, 50, 1020-1024.

Ganz, W., and Swan, H. J. C. (1972). Measurement of blood flow by thermodilution. American fournal of Cardiology, 29, 241-246.

Graham, T. P., Jr., Covell, J. W., Sonnenblick, E. H., Ross, J., Jr., and Braunwald, E. (1968). Control of myocardial $\infty$ oxygen consumption: relative influence of contractile state $ᄋ$ and tension development. Fournal of Clinical Invest.gation, 47, 375-385.

Gray, R., Chatterjee, K., Vyden, J. K., Ganz, W., Forrester, J. S., and Swan, H. J. C. (1975). Hemodynamic and metabolic effects of isosorbide dinitrate in chronic congestive heart $\Phi$ failure. American Heart fournal, 90, 346-352.

Higgins, C. B., Millard, R. W., Braunwald, E., and Vatner, S. F. (1973). Effects and mechanisms of action of dopamine $\infty$ on regional hemodynamics in the conscious dog. American fournal of Physiology, 225, 432-437.

Loeb, H. S., Winslow, E. B. J., Rahimtoola, S. H., Rosen, K. M., and Gunnar, R. M. (1971). Acute hemodynamic effects of dopamine in patients with shock. Circulation, 44, 163-173.

Mantle, J. A., Russell, R. O., Jr., Moraski, R. E., and Rackley, C. E. (1976). Isosorbide dinitrate for the relief of severe heart failure after myocardial infarction. American fournal of Cardiology, 37, 263-268.

Mark, A. L., lizuka, T., Wendling, M. G., and Eckstein, J. W. (1970). Responses of saphenous and mesenteric veins to the administration of dopamine. Fournal of Clinical Investigation, 49, 259-266.

Mason, D. T., and Braunwald, E. (1965). The effects of nitroglycerin and amyl nitrite on arteriolar and venous tone in the human forearm. Circulation, 32, 755-766.

Williams, D. O., Bommer, W. J., Miller, R. R., Amsterdam, E. A., and Mason, D. T. (1977). Haemodynamic assessment of oral peripheral vasodilator therapy in chronic congestive cardiac failure: prolonged effectiveness of isosorbide dinitrate. American fournal of Cardiology, 39, 84-90.

Yang, S. S., Bontivoglio, L. G., Maranhao, V., and Goldberg, H. (1972). In From Cardiac Catheterisation Data to Hemodynamic Parameters, p. 9. F. A. Davies, Philadelphia.

Requests for reprints to Dr J. D. Stephens, Department of Cardiology, St. Bartholomews Hospital, West Smithfield, London EC1A 7BE. 